Pediatric burns are the third most common causes of accident-induced mortality following motor vehicle accidents and drowning. After burn, patients are exposed to many stressors that lower sleep quality and interrupt sleep. Treatment-associated factors such as fixation methods, physiological factors, therapeutic interventions, diagnostic procedures, mechanical ventilation, sedatives, analgesic and anesthetic drugs are known to affect sleep. Thermal injuries cause increases in sleeplessness, and significant reductions in non-REM sleep and REM sleep.

Aim: This present study was planned to determine sleep characteristics, sleeplessness and sleep habits in pediatric burn patients.

\section{MATERIALS METHODS}

Settings:The study was designed as a descriptive one and carried out with 96 children who were 2-6year-old in Pediatric Surgery Department/Burn Unit for 2-7 days. For data collection; Demografic Data Collection Form, Sleep Problems Characteristics and Identification Survey which has been created by researchers are used. Data were collected by face to face interviews with mothers. Questions were asked to compare pre-post burn sleep quality. At the age of 0-2; there are multiple phase sleep patterns and an equal number of sleeping and awakening periods during the day and night. Babies are polyphasic, preschool children sleep biphasic. Physiological biphasic sleep pattern becomes a monophasic night sleep with the necessity of school life. For this reason, children aged 2 to 6 years with biphasic sleep were studied.

The data obtained from the study were analyzed using the SPSS version 21.Statistical significance was established at a $p$ value $<0.05$.

\section{RESULTS}

The participating children's mean age was $3.36 \pm 1.39$ and of the children $53.1 \%$ were male The part of the body exposed to burns most in children $(10.4 \%)$ was the "hands". Of the children in the study, $79.2 \%(n=76)$ had second-degree burns. The mean percentage of burns was $8.12 \% \pm 5.61(\mathrm{~min}: 1 \%$, $\max 30 \%$ ). Of the causes of burns in children, $47.9 \%$ were hot water.

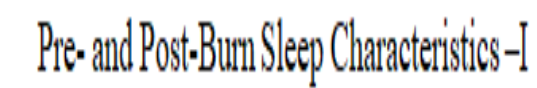

\begin{tabular}{|c|c|c|c|c|c|c|}
\hline & & Mean & SD & Vín-Nax Values & t & p \\
\hline \multirow{4}{*}{$\begin{array}{l}\text { Tale upime in } \\
\text { the moning }\end{array}$} & Proburn & 8:48...m. & 1.14 & IIin.5 & \multirow{4}{*}{10.023} & \multirow{4}{*}{0.001} \\
\hline & & & & Max: II & & \\
\hline & Postiblun & 6.96a.m. & 1.09 & لlini:! & & \\
\hline & & & & Inax:9 & & \\
\hline \multirow{4}{*}{$\begin{array}{l}\text { Duration of of midit } \\
\text { slepg }\end{array}$} & Pryeburn & 10.83 hours & 1.13 & Wining hours & \multirow{4}{*}{13.644} & \multirow{4}{*}{ 40.001 } \\
\hline & & & & Mara: 12 howrs & & \\
\hline & Postbourn & 7.44 hours & 1.79 & Winn:3hours & & \\
\hline & & & & Vara: 12 hours & & \\
\hline \multirow{4}{*}{$\begin{array}{l}\text { Duration of } \\
\text { daytme sleep }\end{array}$} & Preb-birin & 1.46 hours & 1.07 & Ninin: Ohours & \multirow{4}{*}{-1.307} & \multirow{4}{*}{194} \\
\hline & & & & Men: 3 hours & & \\
\hline & Positblutin & 1.67 hours & 1.01 & Win: Ohours & & \\
\hline & & & & Max: 6 hours & & \\
\hline \multirow{4}{*}{$\begin{array}{l}\text { Dustion ofdally } \\
\text { slepp }\end{array}$} & Prebluin & 11.56hours & 1.40 & Win: 8hours & \multirow{4}{*}{8.715} & \multirow{4}{*}{0.001} \\
\hline & & & & Man: 15 hours & & \\
\hline & Postblunn & 9.13 hours & 2.07 & Vint thours & & \\
\hline & & & & Max: II hours & & \\
\hline
\end{tabular}

Pre-PostBurn Sleep Characteristics-II

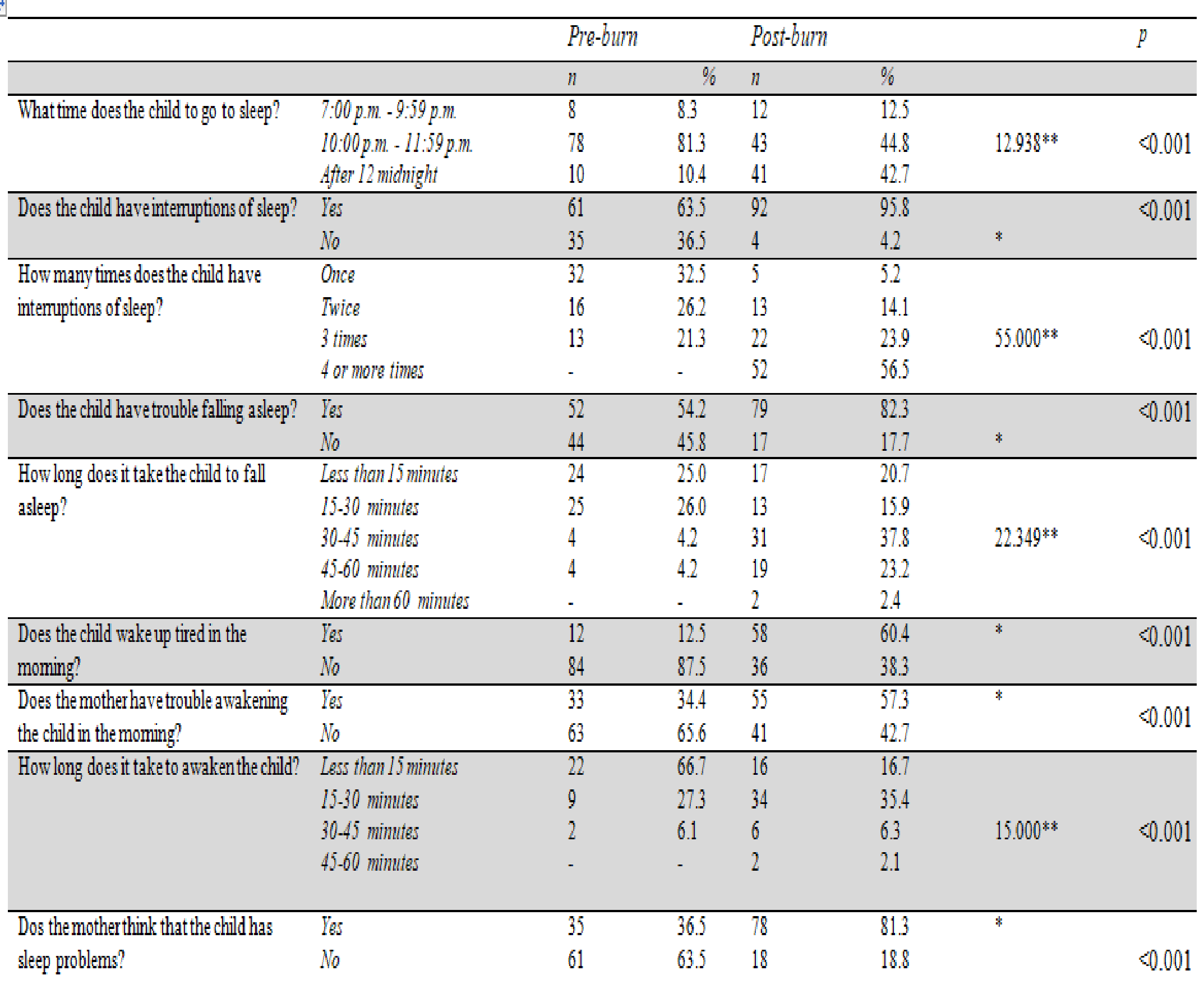

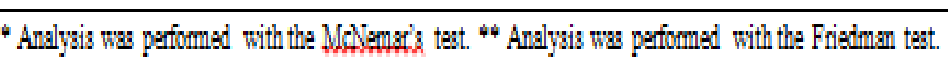

Comparison of Pre-Post Burn Sleep Habits

\begin{tabular}{|c|c|c|c|c|c|c|c|c|}
\hline \multirow[b]{3}{*}{ The child; } & \multicolumn{4}{|c|}{ Pre burn } & \multicolumn{3}{|c|}{ Postburn } & \multirow[t]{3}{*}{$p$} \\
\hline & \multicolumn{2}{|c|}{$\begin{array}{l}\text { Never } \\
\text { Occasionally }\end{array}$} & \multicolumn{2}{|c|}{$\begin{array}{l}\text { Frequently } \\
\text { Every night }\end{array}$} & \multicolumn{2}{|c|}{$\begin{array}{l}\text { Never } \\
\text { Occasionally }\end{array}$} & $\begin{array}{l}\text { Frequently } \\
\text { Every night }\end{array}$ & \\
\hline & $\mathrm{n}$ & $\%$ & $\mathrm{n}$ & $\%$ & $\mathrm{n}$ & $\%$ & $\mathrm{n} \%$ & \\
\hline has trouble falling asleep (needs a parent) & 69 & 71.9 & 27 & 28.1 & 12 & 12.5 & $84 \quad 87.5$ & $<0.001$ \\
\hline has trouble falling asleep at night again after waking up & 67 & 69.8 & 29 & 30.2 & 16 & 16.7 & 8083.3 & $<0.001$ \\
\hline $\begin{array}{l}\text { wants a pacifier when he she wakes up at night, wants his her parent to } \\
\text { put the pacifier back to his her mouth }\end{array}$ & 66 & 68.8 & 30 & 31.3 & 53 & 55.2 & $43 \quad 44.8$ & .004 \\
\hline wants to drink something ovemight (Sucking Mother's Breast or bottle) & 86 & 89.6 & 10 & 10.4 & 68 & 70.8 & $28 \quad 29.2$ & $<0.001$ \\
\hline is afraid of sleeping alone & 75 & 78.1 & 21 & 21.9 & 30 & 31.3 & $66 \quad 68.8$ & $<0.001$ \\
\hline is afraid of sleeping in the dark & 79 & 82.3 & 17 & 17.7 & 46 & 47.9 & $50 \quad 52.1$ & $<0.001$ \\
\hline hugs an object while falling asleep (blanket, toy, bottle etc.) & 70 & 72.9 & 26 & 27.1 & 71 & 74.0 & $25 \quad 26.0$ & $>0.05$ \\
\hline $\begin{array}{l}\text { is anxious and restless during the day because of not having enough } \\
\text { sleep at the previous night }\end{array}$ & 80 & 83.3 & 16 & 16.7 & 30 & 31.3 & $66 \quad 68.8$ & $<0.001$ \\
\hline wants to be read books or listen to a lullaby before going to sleep & 74 & 77.1 & 22 & 22.9 & 54 & 56.3 & $42 \quad 43.8$ & $<0.001$ \\
\hline feels restless while sleeping & 95 & 99.0 & 1 & 1.0 & 20 & 20.8 & $76 \quad 79.2$ & $<0.001$ \\
\hline wakes up screaming, crying, wakes up due to a nightmare & 95 & 99.0 & 1 & 1.0 & 23 & 24.0 & 7376.0 & $<0.001$ \\
\hline
\end{tabular}

There was a significant differences between pre and post burn periods on children's sleeping and waking hour, total and night sleep duration, total daily sleep duration, existence of sleep interruption and number of interruptions, trouble of falling asleep and sleep latency, being tired in the morning, forcing the children to wake up, duration of waking up.

With the knowledge about the importance of sleep, attention should be paid to sleep of children that we are providing care. Supportive environmental regulations should be made to improve the quality of sleep in hospitals. 